\title{
Uninformed Decisions? The Online Presentation of Success and Failure of IVF and Related Methods on German IVF Centre Websites
}

\author{
Entscheidung ohne Information? Die Darstellung von Erfolg und Misserfolg \\ der IVF und angrenzender Methoden auf den Websites deutscher IVF-Zentren
}

Authors

Affiliation
S. Kadi, U. Wiesing

Institut für Ethik und Geschichte der Medizin, Eberhard Karls Universität Tübingen, Tübingen
Key words
- IVF
- success rates
- patient information
- internet
- assisted reproductive technology (ART)

\section{Schlüsselwörter - IVF \\ - Erfolgsraten \\ - Patienteninformation \\ - Internet \\ - assistierte Reproduktions- technologien (ART)}

Deutsche Version unter: www.thieme-connect.de/ ejournals/gebfra

\section{received 17.8.2015 \\ revised 25.10.2015 \\ accepted 26.10.2015}

\section{Bibliography}

Dol http://dx.doi.org/

10.1055/s-0035-1558297

Geburtsh Frauenheilk 2015; 75:

1258-1263 @ Georg Thieme

Verlag KG Stuttgart - New York . ISSN 0016-5751

\author{
Correspondence \\ Dr. Selma Kadi \\ Eberhard Karls Universität \\ Tübingen \\ Institut für Ethik und Geschichte \\ der Medizin \\ Gartenstraße 47 \\ 72074 Tübingen \\ selma.kadi@uni-tuebingen.de
}

\section{Abstract \\ $\nabla$}

Background: Patients increasingly use the internet as a source of medical information before initial contact with doctors and during treatment. This applies to reproductive medicine too, where the internet could offer patients the chance to inform themselves in advance about specific procedures and the treatment centres that offer them. In this way it could potentially contribute to informed patient decision-making. This article analyses the web presence of German fertility treatment centres with respect to the provision of information on success rates, risks and side effects of treatment.

Methods: Analysis of published success rates and information on the risks and adverse effects of IVF and related methods on German IVF centre websites.

Results: Over half of the 129 centres (62.02\%) state a general success rate or their own institution's success rate. Less than a quarter (24.03\%) states their own institution's pregnancy rate and only $7.75 \%$ their own birth rate. The published success rates are mostly pregnancy rates (pregnancy per embryo transfer), which by definition are higher than baby take-home-rates creating unrealistic expectations. Only 61 centres (47.29\%) mention risks and side effects of the procedures offered, and that in varying detail. Only 7 centres (5.43\%) provide information on the risk of psychological stress associated with unsuccessful fertility treatment.

Conclusion: There is insufficient opportunity for women and their partners to inform themselves adequately on the internet in advance of treatment about available treatment methods, their success rates and associated risks/side effects; this applies both to specific facilities as well as to the procedures in general. In contrast to other countries, in Germany there is a lack of discussion on content requirements for fertility treatment facility websites.

\section{Zusammenfassung \\ $\nabla$}

Hintergrund: Das Internet dient zunehmend der Information von Patienten vor dem ersten Arztkontakt und während der Behandlung. Auch in der Reproduktionsmedizin könnte es die Möglichkeit bieten, sich vorab über die einzelnen Maßnahmen und die anbietenden Zentren zu informieren. Damit könnte es zur informierten Entscheidungsfindung von Patienten beitragen. Hier werden die Internetauftritte der reproduktionsmedizinischen Zentren in Deutschland in Bezug auf die Informationen über Erfolgsquoten sowie Risiken und Nebenwirkungen der Methoden untersucht.

Methode: Analyse der veröffentlichten Erfolgsquoten und Angaben zu Risiken und Nebenwirkungen von IVF und angrenzenden Methoden auf Websites von IVF-Zentren in Deutschland. Ergebnisse: Mehr als die Hälfte der 129 Zentren $(62,02 \%)$ veröffentlichen allgemeine oder eigene Erfolgsquoten. Weniger als ein Viertel (24,03\%) gibt eigene Quoten für Schwangerschaften an, und nur 7,75\% die Geburtenrate des jeweiligen Zentrums. Die genannten Erfolgsraten sind meist Schwangerschaftsraten (Schwangerschaft pro Embryonentransfer), die naturgemäß höher sind als die Baby-take-Home-Raten und unrealistische Erwartungen erwecken. Nur 61 Zentren (47,29\%) äußern sich in unterschiedlichem Ausmaß zu den Risiken und Nebenwirkungen der Interventionen. Über das Risiko der psychischen Belastung nach einer erfolglosen reproduktionsmedizinischen Behandlung informieren nur 7 Zentren (5,43\%). Schlussfolgerungen: Die Frauen bzw. Paare haben nur unzureichende Möglichkeiten, sich vorab im Internet über die Verfahren, deren Erfolgsquoten sowie Risiken und Nebenwirkungen zu informieren, sowohl in Bezug auf das einzelne Zentrum als auch allgemein in Bezug auf die Methoden. Anders als in anderen Ländern fehlt in Deutschland eine Diskussion über die Ausgestaltung der Websites von reproduktionsmedizinischen Zentren. 


\section{Introduction}

\section{$\nabla$}

In recent decades the concept of informed consent has become increasingly important in clinical research and practice. With very few exceptions it has become a prerequisite for all medical interventions. Increasingly patients are informed via new media forms, not only in discussion with their doctors but often even before the first clinical contact and during treatment. Recent studies have shown that health related information seeking increasingly takes place on the internet $[1,2]$ so that the information published on this platform is increasingly important.

IVF centre websites should thus provide potential patients with appropriate, relevant and correct information. For those considering IVF, success rate is one of the most important criteria when deciding on a treatment centre [3]. Diverse factors must be considered if clients are to make an informed decision for a given centre based on an assessment of risks and success rates. Firstly, it is the birth rate (baby take-home-rate) and not the pregnancy rate that is important. And only the actual numbers from which the baby take-home-rate is arrived at allow the validity of the stated rate to be appreciated. A single rate is however insufficient. Since results vary according to the method used and particularly according to age group, only appropriately differentiated, specific success rates allow proper comparison/assessment of the various methods and an estimation of the chances of success. In order to compare treatment centres, institution success rates for the standard patient population from commencement of the very first medication must be published [4]. In addition patients must be informed about the risks and side effects of treatment. In this respect IVF centres should provide a comparison of their results with the national norm. Websites should also inform patients about the risk of psychological consequences following unsuccessful fertility treatment.

The publication of success rates has been the focus of criticism since the early years of IVF treatment. Numerous authors have complained of unrealistic claims that lead to patients overestimating their chances of success (e.g. [5-7]). In addition, in its white paper "The Beginning and End of Human Life", the German medical council determined that "the current success rate of only 10 to 15 per cent urgently needs to be improved" ([8], P. 36). The documented IVF success rate from 1988 was in fact significantly lower than the stated " 10 to 15 per cent" $[9,10]$. Even today evidence based success rates are at best only slightly over 15\% (according to the only partially reliable information from the German in-vitro register [11]), which can hardly be regarded as satisfactory. Thus it is even more important that patients and couples are correctly informed even before first clinical contact with doctors.

The German in-vitro register (DIR) publishes information on general success rates, however the way in which it is presented makes the information incomprehensible to medical laymen. It is also of such poor quality that German fertility clinicians have spoken of a "scandal” ([12], P. 52). The DIR's numbers are incomplete and are based on both prospective and retrospective data, which further reduces their quality $[11,13]$.

There are currently various online calculators that offer the possibility of working out one's own chances of successful fertility treatment*, though they give no information on any particular treatment centre. In contrast to Great Britain, there is no national authority in Germany that publishes success rates with a view to support patients in deciding on a fertility centre. Potential clients have to rely on their own independent research on the individual centre websites. This is the first study to analyse German IVF centre websites with respect to their publication of information on success rates, risks and side effects of fertility treatment.

\section{Materials and Methods \\ $\nabla$}

To assess current publication practice we analysed the websites of 129 German IVF centres. The sample was selected as follows: Firstly all relevant websites were identified. The DIR lists 130 centres for which data are provided from the previous year. One additional centre was a member of the DIR but their data could not be accessed. Data from all 130 centres were extracted from the DIR's annual report. On review of the internet addresses provided a number of websites were found to be duplicated (e.g. one website for numerous facilities without facility-specific information on success rates) or offline. Duplicated websites were considered only once in the further analysis (3 cases). Offline websites were excluded (4 cases). As a second step a search for additional IVF centres was conducted on www.msd-arztsuche.de using the search term "Kinderwunsch" (Engl. the desire to have children). Here 144 websites were found. After correlation with the existing sample only 14 of these 144 websites were new and of these 1 was offline, 2 were already in the sample (e.g. under a different internet address) and 5 centres did not offer IVF or ICSI themselves according to the website information. Thus after 7 exclusions there were 123 cases from the DIR annual report, plus 6 inclusions from the 14 websites identified on www.msd-arztsuche.de making a total of 129 websites in the final sample for analysis.

From March 2015 to July 2015 the study sample websites were assessed using the following two questions:

1. Which success rates are quoted?

2. Which risks and side effects are mentioned?

A descriptive statistical analysis was carried out using the Excel data processing programme. For this purpose the mention frequency of the various success rates (own and general baby takehome-rates, own and general pregnancy rates), risks and treatment side effects was ascertained. In order to better describe the website information being communicated to patients, exact definitions of the stated rates (e.g. cumulative or age-group specific) as well as the rates themselves and the relevance of individual risk factors and side effects were determined.

\section{Results}

Information on the success of IVF and related methods The fertility treatment centres studied only rarely state either their own or the general baby take-home-rate (20 centres, $15.5 \%$ ) ( Fig. 1). The success rates that are mentioned are mostly pregnancy rates (pregnancy per embryo transfer), which are naturally higher than the baby take-home-rate. 78 treatment centres $(60.47 \%)$ state either general or their own pregnancy rates. 31 centres $(24.03 \%)$ publish their own pregnancy rates ( Fig. 2). 10 centres (7.75\%) state their actual birth rates, and 6 of these (4.65\%) also state absolute numbers of births. If one re-

\footnotetext{
* https://www.ivf-success-rates.com/; https://www.sartcorsonline.com/ Predictor/Patient; http://www.ivfpredict.com/index-1.html
} 
gards the baby take-home-rate and absolute numbers of births as essential information for a homepage - since this is the most important information for potential patients - then only $4.65 \%$ of centres fulfil this requirement.

Some treatment centres differentiate their own birth rates according to method (e.g. IVF/ICSI: $25.9 \%$, cryo: $17.1 \%$ ), others according to age category and method (e.g. younger: IVF/ICSI under 31 years $47 \%$ and older: IVF/ICSI over 40 years approx. $4 \%$ ). Others state cumulative birth rates (e.g. 1 cycle $28 \%$ up to 6 cycles $73 \%$ ) or a baby take-home-rate of "over thirty per cent". Even comparing the 10 centres that state their own birth rates is complicated since they cite different measures (e.g. differently defined age categories). Thus medical laymen cannot actually choose a centre based on its success rate as the success rates themselves cannot be directly compared.

Quoted numbers differ substantially between treatment centres. The so-called cumulative likelihood of pregnancy for specific patient groups is sometimes quoted above $90 \%$ (e.g. up to 30 years, 5 treatment cycles; under 36 years, more than 5 cycles), pregnancy rates for other patient groups however are below $10 \%$ (over 40 years, per ICSI cycle; from 44 years onwards with cryopreserved pronuclear stage embryo transfer). 11 centres state their overall pregnancy rates (average of all the treatments in that centre). These range between approx. 27 and 50\% per embryo transfer, though for 7 centres the stated rate is between 40 and $47 \%$. These numbers are significantly higher than the baby take-home-rate and suggest unrealistic chances of success. One centre does not give any information on its successes stating that the law forbids such publication. This is not true. Correct information on all the above-mentioned points is "legally permitted and usually ethically unobjectionable” ([14], P. 2066).

\section{Information on risks and side effects of IVF and related methods}

The risks most often mentioned are the ovarian hyperstimulation syndrome (57 centres, $44.19 \%$ ) and multiple pregnancy (53 centres, $41.09 \%$ ) ( Fig. 3). Nine centres publish their own statistics on multiple pregnancy or multiple births. 25 centres mention

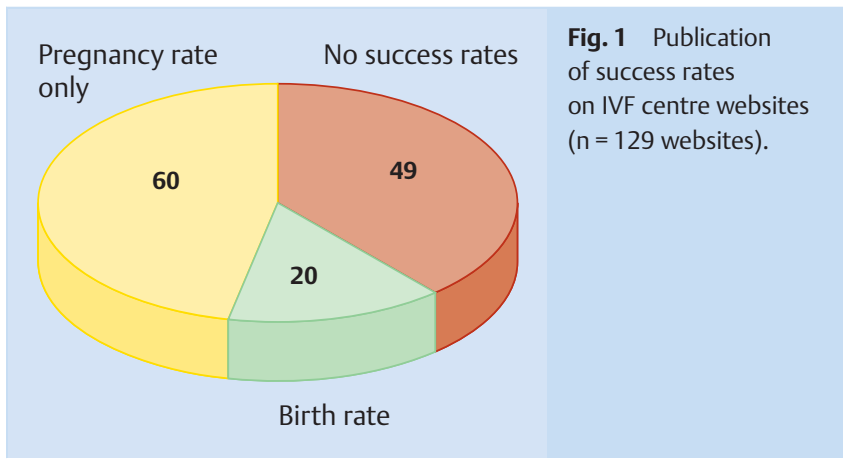

the increased risk of miscarriage, 23 (17.83\%) mention the operative risks of follicle puncture and 21 (16.28) tubal pregnancy. 19 centres (14.73) suggest there is a risk of fetal malformation, 3 centres (2.33\%) claim such a risk is disputed, and a further 3 state that no such risk exists. 8 (6.20\%) of the 19 centres that assume a risk of malformation exists emphasise that it is not due to the methods of artificial insemination used but rather to the patient population using these methods. Treatment centres thus provide contradictory information on the risk of fetal malformation.

In addition 6 centres (4.65\%) mention general pregnancy complications and $3(2.33 \%)$ the risk of absent follicles and absent embryos for transfer. Six centres (4.65\%) explicitly allude to the psychological stress of fertility treatment with IVF and associated methods. 12 centres (9.3\%) recommend psychotherapeutic support or psychological counselling. Only 7 centres mention the psychological consequences of an unsuccessful IVF attempt. As such, only a small minority of treatment centres (5.4\%) consider it worth mentioning the most common risk of all.

\section{Discussion}

In Anglo-Saxon countries the publication of success rates is mandatory $[15,16]$. The American Society for Assisted Reproductive

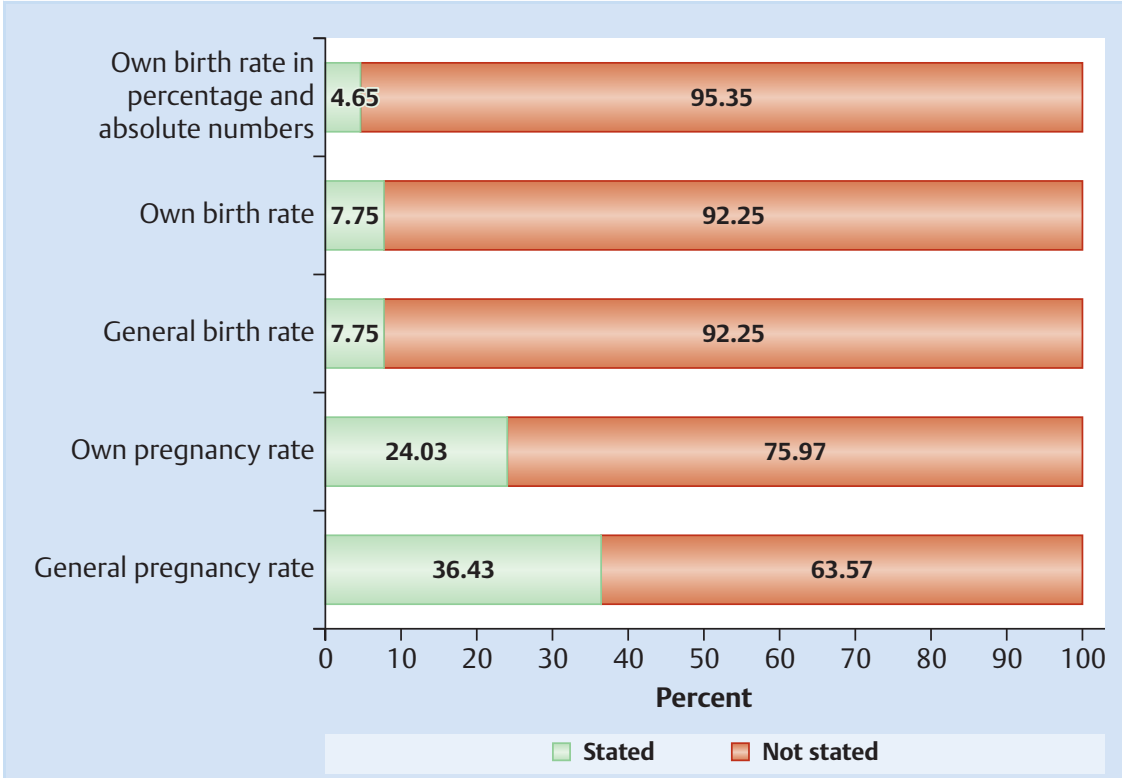

Fig. 2 Publication of various success rates on IVF centre websites ( $n=129$ websites). 


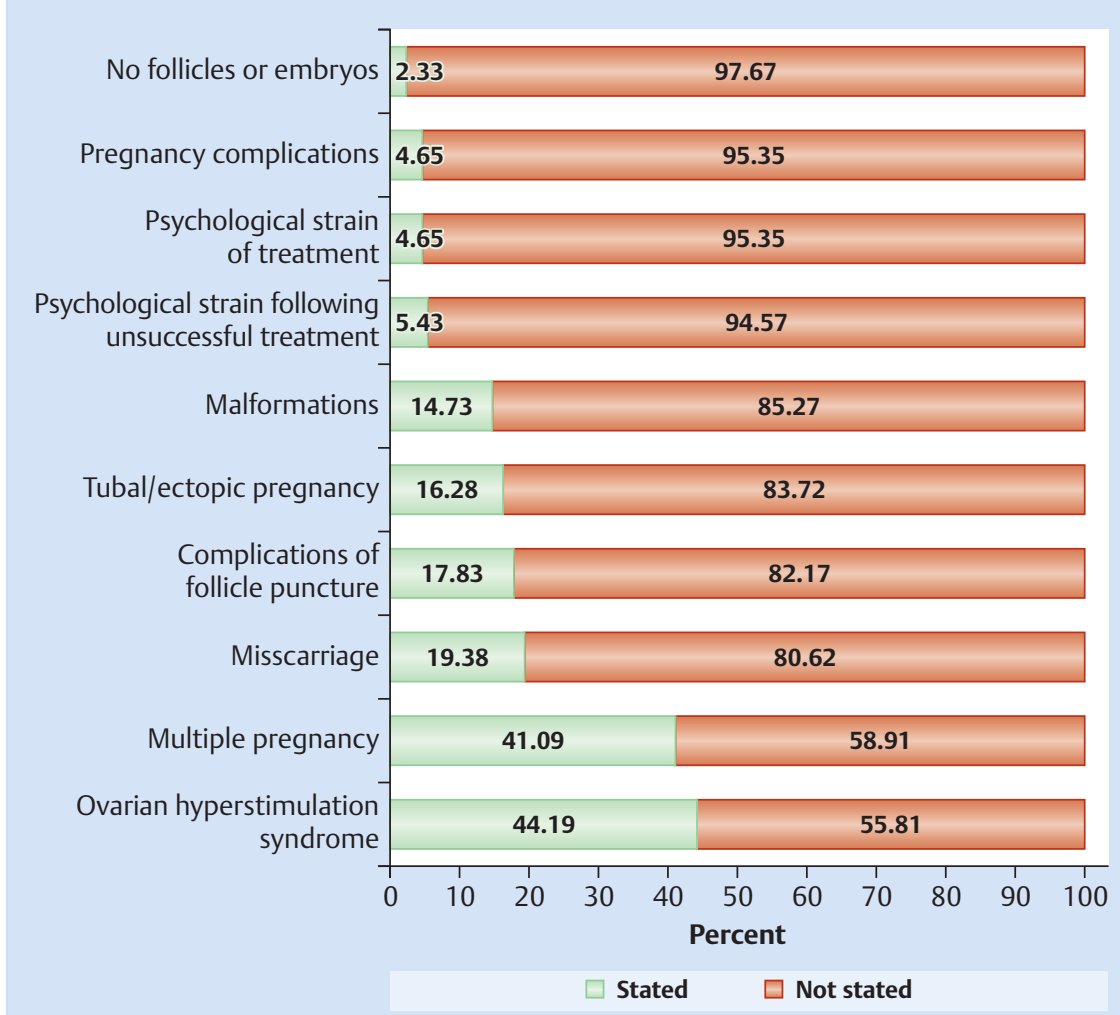

Fig. 3 Risks and side-effects mentioned on IVF centre websites ( $\mathrm{n}=129$ websites).
Technology (SART) suggests its members state their rate of live births per treatment cycle, follicle puncture and embryo transfer, as well as the number of treatment cycles and average number of embryos transferred according to SART-specified age categories [15]. The British Human Fertilisation and Embryology Authority (HFEA) requires - in addition to live birth rates and the associated absolute numbers - the publication of data from the previous three years and data according to patient age and treatment method. Centres should also refrain from plugging rates that are only valid for a small group of patients. In addition, every centre must compare their results with the national average [16]. In recent years international studies have highlighted the poor quality of IVF centre websites in other countries too, particularly with regard to the publication of success rates. Huang et al. evaluated the websites of SART member clinics according to the American Medical Association (AMA) guidelines [17]. They found that only two thirds of clinics had functioning websites and the general quality of the websites was poor.

In a commentary, Jain and Barbieri criticize that the AMA guidelines apply to websites whose main purpose is providing information, and not to medical practice websites that offer specific services [18]. They highlight the special importance of the publication of IVF success rates, which they regard as the most important factor in determining a website's quality. In 2007 Abusief et al. [19] analysed SART clinic websites on the basis of the joint guidelines of the American Society for Reproductive Medicine (ASRM) and SART. The majority of clinics did not adhere to the guidelines set out for SART members. 51\% published success rates, however less than half of clinics published the required absolute numbers behind the calculated rates and only $22.15 \%$ quoted number of live births. In a British study Marriot et al. evaluated websites containing information on IVF according the three criteria (credibility, accuracy and navigability) [20]. They in- cluded various websites in the analysis, not only those advertising a particular IVF centre. Overall, values were low for credibility and accuracy and only somewhat better for navigability. Public health system websites (National Health Service, NHS) scored better than those of private clinics, $40 \%$ of which published no success rates or no specific information on how their published rates were arrived at.

In Germany there are currently no publication guidelines for success rates or information on risks and side effects of IVF and associated methods. There are also no studies evaluating what individual centres actually publish.

In recent decades there has been increased emphasis on informed consent both in the context of research as well as in clinical practice and this has contributed to a change in the doctorpatient relationship. The significance of information communicated to patients on chances of success and the risks and side effects of treatment has increased. Additionally, patients are increasingly using the internet for information before their first clinical contact and during treatment.

The information German IVF centres publish on their websites is variable, often contradictory and generally of extremely poor quality. Our analysis shows that $37.98 \%$ of websites provide no success rates at all while only just over a quarter (25.58\%) of German facilities publish their own success rates. Only $7.75 \%$ of centres provide the key index relevant to patients - the centre's own baby take-home-rate, and only 6 centres (4.65\%) give the absolute numbers behind this rate. The rates are not always current and when compared to DIR rates sometimes apply to different years. Even the centres that do publish rates seldom use the same indices so that in actual fact it is not possible for patients to make direct comparisons.

The information provided on risks and adverse effects of treatment is equally incomplete and presented in a controversial 
manner. Only two treatment risks, the ovarian hyperstimulation syndrome and multiple pregnancy are mentioned by more than $20 \%$ of centres. Only $5.4 \%$ of centres mention one of the most common complications: the psychological consequences of unsuccessful fertility treatment. More than half of centres (52.71\%) provide completely inadequate information on risks and side effects, namely none.

The differing information provided on the risk of fetal malformation is unacceptable. Answering the empiric, scientific question is beyond the scope of this article however: either there is scientific evidence, in which case different centres should not provide differing information, or the evidence is controversial, in which case patients should be informed about this controversy. The fact that some centres maintain there is an increased risk while others state the opposite, puts the scientific nature of a whole discipline under question.

Couples considering fertility treatment cannot adequately inform themselves on the basis of information provided by German IVF centre websites. It is practically impossible to choose between IVF centres based on valid and comparable information. Success rates according to age and indication are required in order to make such choices, however a minority of centres publish their success rates. Quoted numbers also often exaggerate actual chances of success since they reflect the results of single steps along the intervention pathway. The all-important baby takehome-rate is naturally lower than success rates for individual treatment steps, and yet it is only this lowest number that is relevant to the patient. Thus Kenntenich and Tandler-Schneider's findings are not surprising: that couples interested in fertility treatment "overestimate the probability of having a child using artificial insemination and underestimate the problems associated with multiple pregnancy and the risks of treatment" ([21], P. 1145; see also [22]).

When a centre quotes scientifically correct data, yet through selective presentation of these data encourages unrealistic expectations of success, it strikes in an ominous way at the very core of medicine. A successful single step along the fertility treatment pathway may be meaningful for science but has no meaning for the women whose desire to have a child remains unfulfilled. Thus there is a wide gap between scientific "success" and the help that women require. When treatment steps are quoted as success, the medical fraternity makes itself rather than the patient the reference point of success [10]. It alienates itself from its own basic task. Moreover, medical advertisement is legally forbidden and ethically unacceptable "if it promises insufficiently proven benefits" ([14], P. 2067).

The DIR publications cannot replace information that is missing from IVF centre homepages. They are incomprehensible to medical laymen and scientifically of poor quality, since data on births are not available for all treatments in Germany even two years after treatment commencement (see e.g. [11]). The DIR's annual report does not contain information on the success rates of individual treatment centres and as such does not support potential patients in their choice of fertility treatment facility.

In order to improve the currently heterogeneous and deficient practice of online success rate publication guidelines are required. Whereas other countries have specific guidelines for IVF centre websites, in Germany no such guidelines exist and there is no discussion on content requirements for IVF centre homepages. In view of current publication practice such guidelines appear to be urgently needed. Website guidelines and their enforcement are important steps towards better provision of patient in- formation. The German medical council's central ethics commission has in fact made a general proposal to this effect that could be applied to fertility treatment centres [14]. Furthermore, an institution is required that can deliver reliable data on success rates, risks and treatment side effects throughout Germany in order to allow a comparison of individual centres with a national average. The data supplied by the DIR do not fulfil this requirement.

\section{Conclusion}

This analysis of website-based online information communication to patients shows that only $7.75 \%$ of 129 German IVF centres publish their facility's actual birth rate. In contrast to other countries there are no guidelines to this effect in Germany.

\section{Conflict of Interest}

$\nabla$

None.

\section{References}

1 Zschorlich B, Gechter D, Janßen IM et al. Gesundheitsinformationen im Internet: Wer sucht was, wann und wie? Z Evid Fortbild Qual Gesundhwes 2015; 109: 144-152

2 Rossmann C. Gesundheitskommunikation im Internet: Erscheinungsformen, Potenziale, Grenzen. In: Schweiger W, Beck K, Hrsg. Handbuch Online-Kommunikation. Wiesbaden: Springer VS Verlag für Sozialwissenschaften: 2010: 338-363

3 Marcus HJ, Marcus DM, Marcus SF. How do infertile couples choose their IVF centers? An internet-based survey. Fertil Steril 2005; 83: 779-781

4 Sharif $K$, Afnan M. The IVF league tables: time for a reality check. Hum Reprod 2003; 18: 483-485

5 Blackwell RE, Carr BR, Chang RJ et al. Are we exploiting the infertile couple? Fertil Steril 1987; 48: 735-739

6 Soules MR. The in vitro fertilization pregnancy rate: let's be honest with one another. Fertil Steril 1985; 43: 511-513

7 Wiesing U. Ethik, Erfolg und Ehrlichkeit: Zur Problematik der In-vitroFertilisation. Ethik Med 1989; 1: 66-82

8 Bundesärztekammer. Weißbuch Anfang und Ende menschlichen Lebens: Medizinischer Fortschritt und ärztliche Ethik. Köln: Deutscher Ärzte-Verlag; 1988

9 Hölzle C, Wiesing $U$. In-vitro-Fertilisation - ein umstrittenes Experiment. Berlin, Heidelberg, New York, London, Paris, Tokyo, Hong Kong, Barcelona: Springer; 1991

10 Wiesing $U$. Medicine and Hubris - the Case of reproductive Medicine. In: Deltas C, Kalokairinou EM, Rogge S, Hrsg. Progress in Science and the Danger of Hubris. Münster, New York, München, Berlin: Waxmann; 2006: 127-136

11 DIR. Jahrbuch 2013 Deutsches IVF Register. 2014. Online: http://www. deutsches-ivf-register.de/perch/resources/downloads/141117dirjb2013-deweb2.pdf; last access: 07.08.2015

12 Rjosk HK, Haeske-Seeberg H, Seeberg B et al. IVF und GIFT - Ergebnisse in Deutschland 1993. Fertilität 1995; 11: 8-54

13 Enquete-Kommission Recht und Ethik in der Medizin. Schlussbericht. 2002; 1-280. Online: http://dip21.bundestag.de/dip21/btd/14/090/ 1409020.pdf; last access: 07.08.2015

14 Zentrale Kommission zur Wahrung ethischer Grundsätze in der Medizin und ihren Grenzgebieten (Zentrale Ethikkommission) bei der Bundesärztekammer. Werbung und Informationstechnologie: Auswirkungen auf das Berufsbild des Arztes. Dtsch Ärztebl 2010; 107: 2063-2068

15 SART. SART policy for advertising by ART programs. 2015. Online: http://www.sart.org/uploadedFiles/Affiliates/SART/ SART_Links/SART_POLICY_FOR_ADVERTISING_BY_ART_PROGRAMS_ effective_1-2015.pdf; last access: 07.08.2015

16 Human Fertilisation and Embryology Authority Code of Practice. 2015. Online: http://www.hfea.gov.uk/docs/HFEA_Code_of_Practice_ 8th_Edtion_\%28Apr_2015\%29.pdf; last access: 07.08.2015 
17 Huang JYJ, Discepola F, Al-Fozan $\mathrm{H}$ et al. Quality of fertility clinic websites. Fertil Steril 2005; 83: 538-544

18 Jain T, Barbieri RL. Website quality assessment: mistaking apples for oranges. Fertil Steril 2005; 83: 545-547

19 Abusief ME, Hornstein MD, Jain T. Assessment of United States fertility clinic websites according to the American Society for Reproductive Medicine (ASRM)/Society for Assisted Reproductive Technology (SART) guidelines. Fertil Steril 2007; 87: 88-92
20 Marriott JV, Stec P, El-Toukhy T et al. Infertility information on the World Wide Web: a cross-sectional survey of quality of infertility information on the internet in the UK. Hum Reprod 2008; 23: 15201525

21 Kentenich H, Tandler-Schneider A. Die Arztrolle in unterschiedlichen klinischen Kontexten: Ärztliche Beratung bei In-vitro-Fertilisation (IVF) und Präimplantationsdiagnostik (PID). Bundesgesundheitsblatt 2012; 55: 1144-1153

22 Revermann C, Hüsing B. Fortpflanzungsmedizin - Rahmenbedingungen, wissenschaftlich-technische Entwicklungen und Folgen: Endbericht zum TA-Projekt. Berlin: TAB; 2010 